\title{
TV Vanguarda e os desafios da migração do analógico ao digital
}

Vanessa Vantine

Jornalista, especialista em Gestão da Comunicação pela Escola de Comunicações e Artes da Universidade de São Paulo.

E-mail: vanessavantine@hotmail.com

Ademir Ribeiro

Jornalista, especialista em Gestão da Comunicação pela Escola de Comunicações e Artes da Universidade de São Paulo.

E-mail: ademiribeiro@gmail.com

Resumo: O presente artigo faz uma reflexão sobre a convergência das mídias e também analisa a atual mudança de sistemas analógicos para digitais, além de buscar entender as transformações que já começam a despontar com a implantação da TV Digital interativa. Nesse cenário, a cultura digital e a recente geração, que tem como referência essa realidade, são analisadas. O objeto de estudo é a TV Vanguarda - afiliada da Rede Globo no Vale do Paraíba, interior de São Paulo. O trabalho apresenta propostas para que a emissora faça as adequações necessárias à era digital e também discute sobre o futuro da produção de conteúdo na televisão (e em seu sítio na internet), já que os telespectadores do século XXI querem, cada vez mais, interagir.

Palavras-chave: TV digital, internet, geração digital, educomunicação, TV Vanguarda.
Abstract: This work is a reflection on the convergence of media and also examines the current change of analog to digital systems, and seek to understand the transformations that have begun to dawn with the rollout of digital interactive TV. In this scenario, the digital culture and the recent generation that has reference to that reality are analyzed. The object of study is the TV Vanguarda - affiliate of Rede Globo in Vale do Paraiba, interior of Sao Paulo. The paper presents proposals for the broadcasting television to make the necessary adjustments in the digital age and also discusses on the future production of content in TV (and on its website), as viewers of the XXI Century want to interact.

Keywords: digital TV, Internet, digital generation, educomunicação, TV Vanguarda.

A migração das mídias analógicas para digitais implica mudanças de linguagem, de comportamento e de relacionamento entre as pessoas. Em um novo espaço de interfaces - o virtual -, as relações ocorrem por meio de redes e códigos binários que se combinam instantaneamente. Nesse mundo digital, o tempo e a distância perdem as referências naturais e ganham novas coordenadas. O que antes era distante parece próximo e podemos acessar o longínquo por meio de um simples comando: o clique. 
Nesse novo sistema informatizado, a comunicação passa por transformações bruscas. A convergência entre as mídias propõe uma portabilidade nova (capacidade de assistir à programação em receptores móveis) e um acesso à informação antes impensável. A conexão em rede se alastra acelerando o compartilhamento e o fluxo de dados. Por outro lado, o público atingido tem a possibilidade de interagir com os conteúdos que lhe são ofertados. Filmes, vídeos, músicas, artes gráficas, animação, transmissões de televisão, livros, fotografias e revistas em formato digital adquirem novas proporções.

Dentre as mudanças propostas nesse universo digital está a maneira como hoje recebemos informação em nossas casas por meio da televisão e da internet. No Brasil, estamos acompanhando a implantação da TV digital. Desde 2 de dezembro de 2007, na cidade de São Paulo, o sistema está em operação e outras capitais já recebem o novo sinal.

A TV digital promete, além da qualidade de imagem de cinema, modificar a relação que o telespectador tem com o aparelho de TV através de uma nova linguagem de comunicação - esta que o telespectador já vem vivenciando na internet. Nesse processo de comunicação, o sujeito passa a ter um papel ativo (de linear para não linear). A interatividade e a portabilidade transformam drasticamente a relação dos consumidores com os conteúdos midiáticos.

\section{A PESQUISA}

Atuando como comunicadores na TV Vanguarda, afiliada da Rede Globo no Vale do Paraíba, interior de São Paulo, tivemos interesse especial em estudar esta questão: a recepção de conteúdos na TV Digital. A emissora tem cerca de 170 funcionários e seu sinal abrange 46 cidades da região, com mais de dois milhões de telespectadores. Neste momento, a TV Vanguarda passa por um processo de digitalização e experimenta a nova relação com seus consumidores no site da TV: o Vnews ${ }^{1}$.

Os profissionais de televisão costumam produzir seus conteúdos, sejam eles de entretenimento ou jornalismo, pensando em telespectadores convencionais, com hábitos e costumes moldados pela programação aberta da TV analógica. $\mathrm{O}$ que este estudo pretende demonstrar é que tal pensamento precisa mudar. O momento é de produzir para uma nova geração de teleinternautas, como chamaremos o público que a TV Vanguarda pode conquistar: pessoas que cresceram ou vivem na geração dominada pela televisão, mas que acompanham de perto o desenvolvimento da internet e da era digital.

Para analisar como será essa recepção de conteúdos televisivos na era digital, desenvolvemos pesquisa qualitativa baseada em investigação bibliográfica, coleta de dados de caráter qualitativo por meio de entrevistas com profissionais da área, enquete com internautas e um grupo de foco realizado com estudantes

1. Disponível em: <http:// www.vnews.com.br>. que já estão inseridos no universo digital. 


\section{A TELEVISÃO NA ERA DIGITAL}

A partir do século XX, o desenvolvimento dos meios de comunicação cria novas formas de interação e novas redes de difusão que alteram o cenário da época e geram uma nova realidade. As mídias analógicas desenvolvem processos de humanização tecnológica envolvendo sentimentos e regras de comportamento, como se fossem reais. Em meados do mesmo século, dentre os avanços tecnológicos que interferem e modificam os meios de comunicação, a televisão começa a monopolizar a produção cultural e passa a ser indiscutível e incontestável a sua importância na formação da sociedade contemporânea.

A televisão torna-se, na segunda metade do século XX, a principal mídia da sociedade contemporânea e, efetivamente, o mais complexo veículo de comunicação de massa - por sua linguagem audiovisual com a captação simultânea de imagem e som, pela possibilidade de transmissão das mesmas imagens, ao mesmo tempo, para pontos distantes por sua domesticidade e verossimilhança. [...] Assim, uma cultura homogênea, seriada e de forte impacto sobre o receptor vai se introduzindo no dia a dia das pessoas, criando rituais persistentes de comunicação ${ }^{2}$.

No século XXI, a televisão ainda é o veículo de comunicação mais abrangente, principalmente entre as camadas menos favorecidas da população. Nos últimos anos, entretanto, ela começa a abrir espaço para novas mídias. Os avanços tecnológicos permitem novas conexões de conteúdo, formas rápidas e participativas de comunicação, e os espectadores podem vivenciar experiências mais ativas. O mundo, antes analógico, experimenta uma cultura digital, que é a capacidade de relação dos indivíduos com os inúmeros ambientes que os cercam. Nesse novo espaço integrado e cercado de tecnologia, presenciamos o surgimento da chamada convergência digital.

Foi-se o tempo que havia uma máquina para cada atividade de mídia, seja ela para uso privado ou profissional. Hoje elas convergem em funções e atividades, sendo oferecidas em tamanhos cada vez mais compactos, como é o caso dos Palms e dos aparelhos sem fios que permitem utilizar internet em qualquer lugar do planeta sem necessitar de conexão telefônica. Tratar de convergência tecnológica significa, por exemplo, pensar o uso comum - ou em separado - da TV, rádio, internet, cinema e celulares, assim como a possibilidade de passar arquivos de imagem, texto ou áudio de um para outro aparelho digital e de se construir sozinho ou coletivamente novos conteúdos ${ }^{3}$.

\section{SOCIEDADE EM REDE}

Como referência teórica é preciso buscar reflexões para responder a essa indagação: como a TV, nesse universo tão convergente, deve reagir (ou está reagindo) à "sociedade em rede" ?4 A expressão cunhada por Manuel Castells sintetiza esse complexo de relações mediadas com o qual convivemos e no qual procuramos nos inserir.

\footnotetext{
2. COSTA, Cristina. Ficção, comunicação e mídias. São Paulo: Senac, 2002. p. 49

3. CASTRO, Cosette; BARBOSA FILHO, André. A convergência digital analisada sob o prisma da nova ordem tecnológica. Disponível em: $<$ http://www.compos.org. $\mathrm{br} /$ data/biblioteca 550 . pdf $>$. Acesso em: 17 out. 2008.

4. CASTELLS, Manuel. Internet e sociedade em rede. In: DE MORAES Denis (Org.). Por uma outra comunicação. Rio de Janeiro: Record, 2003.
} 
5. CITELLI, Adilson. Palavras, meios de comunicação e educação. São Paulo: Cortez, 2006. p. 124

6. CASTELLS, op. cit. p. 285.
Nessa sociedade em rede, regida e administrada pela internet, as pessoas não apenas ouvem, leem ou veem, mas têm a capacidade de falar, dizer o que pensam, ler, criar imagens e comunicar-se com outro público. Os espectadores podem se tornar autores dos próprios textos, são capazes de criar a programação que quiserem e podem ainda usufruir de uma possibilidade tecnológica que vem revolucionando o mundo da comunicação: a interatividade. A internet, gerenciadora da sociedade em rede, promove tantas mudanças que já não pode ser vista apenas como novo meio de comunicação. Adilson Citelli, por exemplo, considera a internet um agente reconfigurador das práticas sociais.

De maneira preliminar, entendemos que a internet supera a condição do que é considerado, tradicionalmente, meio de comunicação. Ela representa outra maneira de organizar a experiência humana, configurando sociabilidades, comportamentos, impactando nos fluxos econômico-financeiros, no comércio, enfim, nas múltiplas e variadas instâncias que enformam a vida contemporânea ${ }^{5}$.

Para a sobrevivência social das empresas de comunicação diante dessas mudanças e das novas expectativas que elas geram, os meios de comunicação analógicos convencionais têm de se adaptar - é previsível a necessidade de haver uma mudança de atitude para conquistar principalmente a nova geração acostumada ao dinamismo da internet. Manuel Castells afirma: "A internet está revolucionando a comunicação por sua capacidade de fazer os grandes meios de comunicação entrarem em curto-circuito" ${ }^{\prime \prime}$.

Para a produção de programas nos meios de comunicação, isso significa principalmente que a partir de agora é preciso permitir a participação do telespectador e do internauta na criação de conteúdos, dar voz e espaço ao consumidor, fazendo-o interagir, comunicar, opinar e participar. É necessário que os meios respeitem a complexidade dos receptores, sua diversidade cultural, social, econômica e política. Isso implica ter um novo tipo de receptor, telespectador e consumidor - alguém que pode responder, interagir e participar.

Com essa importância adquirida pelos receptores, é essencial conhecê-lo adequadamente - saber quem são, o que eles querem e o que esperam dos meios de comunicação. Essa tem sido a preocupação também da empresa onde trabalhamos - a Rede Vanguarda, que já atinge uma camada importante da população regional, ou seja, mais de dois milhões de telespectadores. Com o crescimento da internet, é o momento de crescer em direção a esse novo horizonte tecnológico, atingindo um público crescente com a mesma credibilidade alcançada até o momento.

O autor Rogério da Costa comenta essas transformações e a necessária adaptação que elas geram:

Está em curso uma mutação profunda nas formas de comunicação, no modo que as mensagens são construídas e mediadas. Essa mutação é parte da revolução digital que vivemos há mais de uma década. A participação na televisão por telefone, fax ou internet, a TV Digital interativa, a evolução dos agentes inteligentes e sua disseminação a nossa volta, a multiplicação de comunidades virtuais de todo o tipo, a epidemia dos sem-fio são fatos marcantes da cultura digital. Cul- 
tura que cresce sob o signo da interconexão entre dispositivos computacionais, da inter-relação entre os homens em escala planetária, do relacionamento cotidiano com máquinas inteligentes e da obsessão pela interatividade. Cultura que alimenta, no fundo, artifícios extremamente sofisticados para prender a atenção das pessoas, para orientá-las na confusão que ela mesma criou ${ }^{7}$.

No que diz respeito à TV Vanguarda, seria desejável que os comunicadores ficassem atentos à maneira como a sociedade em rede vem alterando a relação entre localismos e globalização. Como a emissora é voltada para um público regional, torna-se necessário tratar de forma diferente esse localismo e a cultura regional, formada de crenças, histórias e hábitos que caracterizam as pessoas da região. Enfrenta-se o duplo desafio de se aproximar mais do público e atender, ao mesmo tempo, a uma audiência que se globaliza. Por isso, a comunicação que se estabelece sob essas influências é tão complexa.

\section{O PROJETO}

Para estudarmos o projeto digital da TV Vanguarda, durante o curso de Gestão da Comunicação da USP, optamos por entrevistar os profissionais responsáveis pela Emissora do Vale do Paraíba: o gerente de engenharia, Sandro Sereno, o gerente de programação, Valério Souza, e a gerente de jornalismo, Terezinha de Almeida. Para termos a certeza do pensamento da empresa na era digital, entrevistamos o principal acionista da TV, José Bonifácio de Oliveira Sobrinho, um dos profissionais mais experientes em televisão no país, que participou da formação da programação e da história da Rede Globo.

Foram realizadas entrevistas abertas, gravadas, transcritas e submetidas à análise de conteúdo, cujos resultados passamos a apresentar. Os entrevistados estão otimistas diante das mudanças tecnológicas e enxergam a televisão como o meio de comunicação mais potente na sociedade, o que deve ocorrer por alguns bons anos ainda. É unânime a opinião de que a internet está crescendo de forma avassaladora, conquistando principalmente a nova geração, mas poucos temem a concorrência entre internet e a televisão. No entanto, todos concordam que a forma de produzir conteúdo deve mudar, principalmente em seu formato, já que a internet exige respostas mais rápidas, curtas e dinâmicas. E para que a televisão conquiste esse novo público é preciso que ela seja mais ágil e que dê mais voz às pessoas, uma vez que a internet permite que o público participe e interaja.

O desafio dessa nova era é trabalhar com um veículo mais complexo, que possibilite interconexões com outras mídias e estabeleça uma comunicação mais inteligente.

O fato é o seguinte: vamos ter conteúdos audiovisuais em todas as coisas; na internet, no telefone, na televisão, não necessariamente convergentes, muitas vezes até divergentes, mas sempre formatados de acordo com a linguagem daquele veículo. A interatividade na televisão é cara, ela depende de você ter uma linha de retorno, porque a televisão transmite digital, mas ela não recebe pelo

7. DA COSTA, Rogério. A cultura digital. São Paulo: Publifolha, 2003. p. 81. 
comunicação \& educação • Ano XIV • Número 3 • set/dez 2009

televisor, você precisa de um telefone, você tem que estar conectado em uma linha telefônica para você poder interagir com a emissora. Mas nós vamos assistir a uma mudança radical na maneira de usar a internet, na maneira de usar a televisão e na maneira de usar o telefone (depoimento de José de Bonifácio Oliveira Sobrinho).

A presença das mídias digitais é entendida pelos entrevistados como um processo em implantação na sociedade. Para eles, daqui a alguns anos, a tecnologia analógica não existirá mais, será substituída. O público, diante desses avanços tecnológicos, já começa a ser pensado como um consumidor que, cada vez mais, exige inovação constante. De acordo com os entrevistados neste estudo, espera-se trabalhar com usuários que, como telespectadores ativos, estabeleçam, eles mesmos, novas formas de troca de conteúdo com o produtor.

Tem um certo medo, sim, de perda de audiência por causa da internet. Tanto que a Globo disponibiliza, mas só depois que foi ao ar. Mas a televisão sobrevive sim a essas mudanças se ela ficar mais inteligente, porque hoje ela ainda é burra. $\mathrm{O}$ que você faz com a TV? Nada. A nova geração que gosta de mexer, fuçar, se cansa da TV rapidinho. Acredito que a TV precisa ficar inteligente imediatamente, ter interatividade, e isso caminha com o surgimento da TV Digital, mas esse processo, eu penso, tem que ser mais rápido pra pegar logo essa nova geração (depoimento de Valério de Souza).

Os entrevistados acreditam que a ligação entre TV e internet deve estar cada vez mais próxima. Hoje não há dúvidas de que é impossível bem informar sem estar presente na rede. A disputa pela audiência não é somente entre canais de televisão, pois no universo digital há uma competição entre veículos de comunicação. Com relação à TV Digital, foi possível identificar que todos os entrevistados entendem que as transformações já começam a acontecer, mas analisam a implantação do novo sistema de forma diferente. Alguns acreditam na necessidade da capacitação dos atuais funcionários; outros entendem que os novos profissionais irão, aos poucos, modificar esse cenário.

Os novos jornalistas já chegam com uma velocidade muito diferente, os estagiários chegam assim. São eles que vão fazer a renovação (depoimento de Terezinha Almeida).

Na opinião da maioria dos entrevistados, a interatividade na televisão não pode acontecer só quando a televisão digital já estiver disponível na região da emissora afiliada. Os telespectadores têm que ser preparados para as mudanças processadas em curso. De acordo com José Bonifácio de Oliveira Sobrinho, essa função também é da emissora, que deve apresentar aos telespectadores as novas formas de comunicação e convidá-los, aos poucos, a produzir conteúdo para a televisão.

Então nós temos que preparar o nosso consumidor para as novas tecnologias, para o novo tipo de comunicação, e, mais do que isso, nós temos que entender que eles precisam ser formados para poder usar a linguagem nova que vai surgir (depoimento de José Bonifácio de Oliveira Sobrinho). 
Em um primeiro momento, a TV Digital pode ser analisada como um equipamento com melhor qualidade de imagem (o que já demanda uma reinterpretação das linguagens audiovisuais utilizadas atualmente na televisão, como desafios estéticos antes só enfrentados pelo cinema; o que exige, sem dúvida, novas formas de captação e edição de conteúdo). Entretanto, a proposta é que a adequação da relação entre emissora e receptores alcance uma importância mais ampla nas políticas de modernização da emissora. Entendemos, contudo, que as mudanças nesse meio devam ser cautelosas, tanto por questões técnicas (as transformações não ocorrerão imediatamente) quanto por motivos culturais (sempre haverá a presença simultânea do espectador tradicional, do espectador ativo e do mero observador pouco atento).

Hoje a tecnologia que temos aqui, a maior parte, é analógica e tem algumas coisas isoladas digitais; mas mais que mudar o equipamento do analógico para o digital, vai mudar o conceito operacional, o processo produtivo todo muda. As fitas acabam, a gente começa a operar com mídias em cartões de memórias, as ilhas que a gente possui hoje, que funcionam máquina a máquina, a gente passa a trabalhar com ilhas não lineares, baseadas no computador. Elas serão interligadas em rede com o servidor central. Isso significa mais qualidade e agilidade, desde que a gente consiga mudar a forma de fazer. A gente não pode pensar nesse novo processo da forma que a gente faz hoje, no mundo analógico (depoimento de Sandro Sereno).

Assim, a preparação dos profissionais que trabalham nesse meio é importante tanto técnica quanto intelectualmente, porque cabe aos comunicadores saber com quem estão conversando e qual será o conteúdo que o espectador quer receber ou, mesmo, coproduzir.

Nós vamos ter sempre, no mundo inteiro, indivíduos ativos e indivíduos passivos. Eu não acredito em uma mudança na humanidade que ela se torne de repente interativa do dia para a noite. O que acontece é que os mais jovens, pessoas com uma nova mentalidade, vão realmente ter uma posição mais ativa. Mas existe o espectador que, mesmo com todas as idades, desde pequeno ele quer simplesmente assistir a um espetáculo. Ele não quer interferir com aquilo, e eu imagino que a interatividade tem um aspecto de curiosidade. Quando uma pessoa começa a mexer com interatividade, ela está muito ativa, depois vai mexer somente quando precisar. Então eu acho que a interatividade ainda não é um prazer, ela é uma necessidade (depoimento de José Bonifácio de Oliveira Sobrinho).

\section{Pesquisa quantitativa}

Para saber quais as expectativas dos internautas do Vnews, postamos no site, por cinco dias, enquete com a seguinte pergunta: "Que novidades você quer ver no Vnews?”. Dos 705 respondentes, 228 escolheram a opção que dá a chance de o usuário publicar notícias, fotos e vídeos. Isso significa um desejo da maioria de participar mais do site. Outras 156 pessoas afirmaram que desejam sugerir pautas para o Vnews e para a Rede Vanguarda. Entre os que 
querem mais vídeos e chats com entrevistados, encontramos 121 indicações. E 118 respostas apontaram a opção que não apresenta mudanças. Uma minoria, 82 internautas, quer uma campanha para aparecer no Vnews e na TV. Abaixo, o resultado da enquete:

Tabela 1 - Enquete

Que novidades você quer ver no Vnews?

$32.4 \%$ - Quero ter a chance de publicar notícias, fotos e vídeos 228 entrevistados

22.1\% - Quero sugerir pautas para o Vnews e para a Rede Vanguarda 156 entrevistados

17.1\% - Chat com entrevistados e mais vídeos da TV no Vnews 121 entrevistados

$16.7 \%$ - O Vnews não precisa dessas novidades 118 entrevistados

11.6\% - Uma campanha para ter a chance de aparecer no Vnews e na TV 82 entrevistados

$\mathrm{O}$ que os teleinternautas querem ver no Vnews? Eles desejam mudanças? E na programação da TV Vanguarda? Estão satisfeitos ou não? Certamente, para saber exatamente quem são os internautas do Vnews e o que eles esperam ver no site, a emissora precisaria encomendar uma grande pesquisa de consumo.

No entanto, para tornar esse estudo o mais próximo possível da realidade, decidimos fazer algumas perguntas para internautas que se inscreveram em promoções divulgadas pela Vanguarda. Os e-mails das pessoas, de várias idades, foram cadastrados no Vnews e enviamos as perguntas para os internautas. Como as promoções foram divulgadas tanto no site quanto na televisão, as pessoas podem ter visto as chamadas em ambos os meios.

Obtivemos 104 respostas válidas (algumas foram descartadas, porque os internautas não souberam responder).

$\mathrm{Na}$ pesquisa, fizemos quatro perguntas para análise quantitativa. As respostas foram apresentadas em cinco alternativas com a possibilidade de escolha de somente uma opção.

Na pergunta 1, o maior número de internautas (quase 58\%) respondeu que prefere navegar no site para ficar bem informado com notícias regionais. Os serviços, como classificados, previsão do tempo etc. também são bem procurados (por cerca de 27\%).

Pergunta 1 - Por que você acessa o Vnews?

a) Por causa dos serviços, como classificados, previsão do tempo, promoções etc.

b) Para ficar bem informado com as notícias regionais.

c) Para entrar nos blogs do site.

d) Para ver os vídeos.

e) Por outros motivos.

Enquanto, na questão 1, ninguém respondeu que navega pelos vídeos, na questão 2, a maioria (42\%) mostrou que quer ver mais vídeos e chats com entrevistados no site. Cerca de $21 \%$ das pessoas demonstraram que pretendem participar mais, ajudando a escolher a programação da emissora; porém, os mesmos $21 \%$ não querem mudanças, com a alegação de que o Vnews não precisa das novidades mencionadas. 
TV Vanguarda e os desafios da migração - Vanessa Vantine e Ademir Ribeiro

Pergunta 2 - Que novidades você quer ver no Vnews?

a) Quero ter a chance de ser um repórter, colocando notícias, fotos ou vídeos.

b) Quero participar da escolha da programação da Rede Vanguarda.

c) Quero um chat com entrevistados e ver mais vídeos da TV no Vnews.

d) Quero uma campanha para ter a chance de aparecer no Vnews e na TV.

e) $O$ Vnews não precisa dessas novidades.

A questão 3 pretendeu analisar se o Vnews está lidando com mais internautas ou com teleinternautas, e saber se o site é bem acessado por pessoas que veem mais televisão ou que raramente a assistem, mas que, de vez em quanto, por algum motivo, chamada ou promoção entram no site. As respostas foram mais equilibradas e demonstraram que há mais internautas (35\%), e que o número de teleinternautas (27\%) também é considerável.

Pergunta 3 - Quando estou com tempo livre em casa...

a) ... fico trocando de canal na televisão.

b) ... vejo a programação da Rede Vanguarda.

c) ... navego na internet.

d) ... vejo TV e navego na internet ao mesmo tempo.

e) ... faço outras coisas, fico longe da TV e da internet.

Na pergunta 4, a maioria respondeu que quer mais programas regionais de entretenimento com novidades (o que pode demonstrar também que algumas pessoas estão acostumadas a ver notícias na internet, mas que preferem se entreter na televisão). Em segundo lugar, a vontade de participar da programação, no site e na TV, empatou com a vontade de ser mais bem informado pela Vanguarda.

Pergunta 4 - Que novidades você quer ver na Rede Vanguarda?

a) Quero ter a chance de participar da programação regional no site Vnews e na TV.

b) Quero ver a programação da Vanguarda na internet e no celular.

c) Quero mais programas regionais de entretenimento.

d) Quero mais programas regionais de notícias.

e) A Rede Vanguarda não precisa dessas novidades.

\section{Grupo de estudo}

O grupo de foco com jovens de São José dos Campos foi realizado com alunos entre 13 e 17 anos da FUNDHAS (Fundação Hélio Augusto de Souza), que participam do núcleo de Educomunicação ${ }^{8}$. Essa instituição, sem fins lucrativos, foi criada pela Prefeitura da cidade em 1987 com o objetivo de atender crianças e adolescentes, de 7 a 18 anos, provenientes de classes de baixa renda, dando-lhes oportunidade de desenvolver a cidadania e possibilidades crescentes de conhecimento e desenvolvimento de potencialidades.

8. A esse respeito, ver: <http://www.usp.br/ nce/>. 
Foi possível constatar que a maioria desses jovens, hoje com média de 15 anos, ainda é essencialmente telespectadora. Mas, diferentemente de seus pais e avós, os mais jovens não conseguem passar horas diante da televisão e não é qualquer programação que os interessa. Com a facilidade de se entreterem com outras ferramentas de comunicação, os jovens entrevistados têm mais autonomia no momento de escolha do tipo de relação que pretendem estabelecer com as mídias.

Suas ambições vão além do que parece desejar o telespectador tradicional. Demonstram perfilar-se com um novo modelo de receptor, que, mais do que assistir, quer contribuir com o que é veiculado na tela. Mas a colaboração que eles almejam oferecer não se limita a sugestões de matérias ou a breves participações em entrevistas - pretendem fazer parte do processo de produção televisivo.

Como os alunos da FUNDHAS participam de núcleos audiovisuais e educomunicativos na Fundação, eles já têm noções e domínio de como acontece a elaboração e produção de conteúdo. Sabem da necessidade do diálogo para a escolha de temas a serem abordados, da divisão de tarefas na fase de produção, da importância de respeitar as diferenças de opiniões. Por isso, com uma postura mais crítica em relação ao que hoje é divulgado pela mídia, eles propõem novas maneiras de produção de informação.

De acordo com a análise dos jovens envolvidos no grupo de foco, a TV Vanguarda deveria ter um canal mais aberto de comunicação com essa nova geração de telespectadores. Além disso, o grupo analisa a convergência das mídias como uma possibilidade de divulgar os vídeos que eles produzem na Fundação. E a TV digital interativa, para eles, pode representar maior abertura de espaço para produções regionais independentes.

\section{CONCLUSÃO}

Devemos observar que as mídias não são nem boas nem más; constituem sistemas técnicos de comunicação que, em si mesmos, são neutros e podem ser empregados para desenvolver ou manipular o processo de comunicação ${ }^{9}$.

O século XXI traz transformações no jeito de as pessoas viverem e se relacionarem; por isso, coloca o domínio da televisão em xeque. É possível que a televisão não perca sua força, sua sedução e seu glamour. É possível também que ela até saia mais forte, rica e atraente dessa revolução gerada pelas mudanças tecnológicas e de atitudes. Entretanto, com toda a certeza, a televisão como a conhecemos hoje deixará de existir.

A internet ainda está em sua infância e já mostra que nasceu para ser livre

Francisco Comunicação e teoria social moderna: introdução aos fundamentos conceituais da publicística. Porto Alegre: Fênix, 1995. p. 78. e para dar liberdade aos seus usuários. Sim, na internet os consumidores são usuários. Na televisão analógica e convencional, são apenas espectadores. Contudo, a hora é do espetáculo participativo, em que todos querem ser usuários, independentemente dos meios que estiverem usando. A internet é democrática porque 
TV Vanguarda e os desafios da migração - Vanessa Vantine e Ademir Ribeiro

nela todos têm voz, todos são livres para pensar, dizer e agir; forma, assim, uma nova geração, que questiona cada vez mais o tal autoritarismo da televisão. Esta, enquanto dominante num vasto mercado, pensa que tal transformação ainda vai demorar... mas a internet tem provado que cresce rapidamente, em meio a crianças que trazem novos anseios e expectativas.

A internet é mais democrática do que os meios de comunicação convencionais porque cede a palavra a seus usuários, porém é fragmentada, dividida em segmentos, nichos e guetos; fala para muitos em variadas linguagens. A televisão, ao contrário, é centralizadora e homogeneizadora.

Com tudo que estudamos com os diferentes autores e que ouvimos de nossos entrevistados, podemos afirmar que a televisão, ao começar a dar voz às massas, mantendo seu potencial unificador do discurso democrático, da moral e da ética, poderá manter sua liderança. Uma liderança que será acompanhada (na TV Digital) por mais inteligência, por uma imagem cada vez melhor e uma conexão maior com seus usuários. É hora de a televisão ter a internet como aliada, como uma criança que ainda vai ensinar muito. O momento é de integração entre esses dois meios tão convergentes. Uma integração que fará bem à internet e, principalmente, à televisão.

\section{REFERÊNCIAS BIBLIOGRÁFICAS}

CANCLINI, Nestor Garcia. Consumidores e cidadãos: conflitos multiculturais da globalização. Rio de Janeiro: UFRJ, 2005.

CASTELLS, Manuel. Internet e sociedade em rede. In: DE MORAES, Denis (Org.). Por uma outra comunicação. Rio de Janeiro: Record, 2003.

CITELLI, Adilson. Palavras, meios de comunicação e educação. São Paulo: Cortez, 2006.

COSTA, Cristina. Ficção, comunicação e mídias. São Paulo: Senac, 2002.

DA COSTA, Rogério. A cultura digital. São Paulo: Publifolha, 2003.

HALL, Stuart. A identidade cultural na pós-modernidade. Rio de Janeiro: Record, 2003.

LÉVY, Pierre. Por uma tecnodemocracia. In: As tecnologias da inteligência. Rio de Janeiro: Editora 34, 1993.

LOPES, Maria Immacolata Vassallo. Pesquisa em comunicação. 8. ed. São Paulo: Loyola, 2005.

MARTÍN-BARBERO, Jesús; GERMAN, Rey. Os exercícios do ver: hegemonia audiovisual e ficção televisiva. São Paulo: Senac, 2001.

ORTIZ, Renato. Mundialização e cultura. In: Uma cultura internacional-popular. São Paulo: Brasiliense, 1998. 
comunicação \& educação • Ano XIV • Número 3 • set/dez 2009

RUDIGER, Francisco R. Comunicação e teoria social moderna: introdução aos fundamentos conceituais da publicística. Porto Alegre: Fênix, 1995.

SOARES, Ismar de Oliveira. Comunicação/Educação: a emergência de um novo campo e o perfil de seus profissionais. Contato Brasília, ano 1, n. 1, jan./mar. 1999.

\section{Endereço eletrônico}

CASTRO, Cosette; BARBOSA FILHO, André. A convergência digital analisada sob o prisma da nova ordem tecnológica. Disponível em: $<$ http://www.compos. org.br/data/biblioteca_550.pdf/>. 